\title{
Analysis of Stiffness Reduction Coefficient of Conventionally Reinforced Concrete Coupling Beams on the Bias of Strut-and-Tie Model
}

\author{
Zhangqi Hu${ }^{1}{ }^{\text {* }}$, Weirong $\mathrm{Lv}^{2}$, Yusheng $\mathrm{Wu}^{1}$ and Miao Zhang ${ }^{1}$ \\ ${ }^{1}$ College of Civil Engineering, Hunan City University, Yiyang 413000, China \\ ${ }^{2}$ College of Civil Engineering, Hunan University of Science and Technology, Xiangtan 411201, China
}

Received 24 May 2020; Accepted 29 September 2020

\begin{abstract}
Stiffness reduction coefficient of coupling beams $(\kappa)$ can reflect the stiffness degradation degree at yield and significantly affect the seismic response and the internal force distribution. However, existing calculation methods do not consider the influencing factors comprehensively and have a limited application scope. To effectively predict the stiffness reduction coefficient of conventionally reinforced concrete coupling beams (CCBs), a simplified analysis model was established, and analysis and parameter modification were also implemented. Then, an equation with comprehensive consideration, wide application, and high accuracy was proposed. The proposed equation was verified by comparison with existing test data and calculation methods, and parametric analysis was performed to investigate the independent factors, including the span-depth ratio, longitudinal reinforcement ratio, stirrup ratio and concrete compressive strength. Results show that the independent factors are related to each other, and the span-depth ratio has the greatest influence on the stiffness reduction coefficient of CCBs. Furthermore, $\kappa$ significantly increases with the longitudinal reinforcement ratio when the coupling beam has a large span-depth ratio, but the stirrup ratio has a bigger role when the span-depth ratio is small. Finally, on the basis of the analysis results, suggestions are made to improve the stiffness reduction coefficient of CCBs. The study results provide a reference for the design and optimization of shear wall and core tube structures.
\end{abstract}

Keywords: Conventionally reinforced concrete coupling beam; stiffness reduction coefficient; strut-and-tie model; effective stiffness

\section{Introduction}

Coupling beams play an important role in shear wall and core tube structures under earthquakes, connecting the wall limbs and transferring the bending moment and shear force. Due to coupling beams are the first seismic line of high-rise buildings, the mechanical properties significantly influence the seismic level of the structures $[1,2]$. In recent years, numerous experimental studies and theoretical analyses on coupling beams have been conducted, leading to great progress in design method and philosophy, but these efforts are mainly focused on shear strength and deformation capacity $[3,4]$.

When structures subjected to moderate or strong earthquakes, coupling beams yield and the stiffness degrades The degradation degree directly affects the internal force distribution and the fundamental period. The stiffness reduction coefficient is defined as the ratio of yield stiffness (effective stiffness) to the initial stiffness, which is measured as an important index in seismic performance. In the design of coupling beams, the stiffness reduction coefficients of coupling beams $(\kappa)$ should be carefully designed firstly because unreasonable $\kappa$ values could lead to errors in seismic calculation, thereby influencing the yielding mechanism and optimization design. Therefore, accurately evaluating $\kappa$ is of great importance.

Thus, researchers have paid increasing attention to the stiffness characteristics of coupling beams, performed finite element analyses, and adopted theoretical methods, but

*E-mail address: huzhangqi0413@163.com

ISSN: $1791-2377$ @ 2020 School of Science, IHU. All rights reserved. doi:10.25103/jestr.135.11 quantitative analyses [5-7] were seldom performed. The stiffness of coupling beams is affected by various factors, but the existing calculation methods[8,9] do not consider these factors comprehensively, leading to the inaccurate estimation of $\kappa$. CCBs are widely used in practical engineering, but the accurate estimation of the stiffness reduction coefficient remains a challenge that requires an urgent solution.

Thus, this study performs model analysis and parameter modification to accurately determine the interaction mechanism of the influencing factors. A novel method for predicting $\kappa$ is proposed with comprehensive consideration, high accuracy, and wide application. Subsequently, parameter analysis is performed to investigate the influence of the span-depth ratio, longitudinal reinforcement ratio, stirrup ratio and concrete compressive strength on $\kappa$. Suggestions are made to improve the stiffness reduction coefficient of CCBs

\section{State of the art}

Given that coupling beams are the first seismic line of shear wall and core tube structures, scholars have conducted numerous studies on coupling beams through tests and finite element analysis. Tian et al. [10,11] conducted a seismic experimental study and performed theoretical analysis on steel-plate-reinforced composite coupling beams (PRCs) with small span-depth ratios and found that most of the shear force is taken over by the steel plate, and the deformation capacity of coupling beams increases. On the basis of Tian's study, seismic tests on PRCs with a medium 


\section{Journal of Engineering Science and Technology Review 13 (5) (2020) 82 - 89}

span-depth ratio were conducted by Hou et al. [12] which verified that PRCs exhibit a ductile failure mechanism and were able to dissipate more energy. High damping concrete was applied by Wang et al. [13,14] to core tubes, which performed well with the embedded steel plate, thus improving the rotation capacity of coupling beams and increasing the energy dissipation. Chen et al. [15] proposed a method for designing the reinforced concrete structures with replaceable coupling beams, and the method was verified by the finite element software ABAQUS. Li et al. [16] applied segmented reinforced CCBs to shear walls and achieved satisfactory results, which demonstrate the strong deformation capacity and good energy consumption of shear walls with such coupling beams. Farsi et al. [17] argued that coupling beams with replaceable steel can not only effectively improve the deformation and energy dissipation capacity of shear walls, but also decrease the damage of wall limbs. The traditional steel-concrete composite beam relies on stud connectors to achieve the necessary shear connection between steel and concrete, but the connection is unreliable when subjected to cyclic load because the connection effect cannot be guaranteed by the low concrete ductility. Thus, Ataei et al.[18] presented a new system in which the precast concrete slab is attached to a steel beam using tensioned high-strength friction-grip bolts in clearance holes as the elements to provide the shear connection; their results show that the structure can form a reliable connection between steel and concrete. Hou et al.[19] proposed a new type of connector in fully assembled steel-concrete composite beams and completed three groups of push-out tests to study the influence of channel types, cyclic loading, and the number of connectors on the shear performance. Their results show satisfactory performance of all the connectors. The coupling beam that uses a hybrid steel truss encased in reinforced mortar has the advantages of easy construction, high shear strength, and good anti-deformation capacity over diagonally reinforced concrete coupling beam (DCB), the reliability of the coupling beam was verified through finite element analysis performed by Chairunnisa et al.[20]. The above-mentioned studies were mainly focused on the shear strength, deformation performance and function reconstruction of coupling beams.

The stiffness characteristics should be considered in structure design because seismic response is a dynamic behavior. However, few studies on stiffness characteristics have been conducted. On the basis of finite element analysis, Huang et al.[21] proposed a formula for predicting the effective stiffness of shear walls, and the calculated values were consistent with the experimental results. Sharifi et al.[22] performed statistical analysis on 154 tests of slender and squat walls and studied the influence of the axial compression, longitudinal reinforcement ratio, and depthwidth ratio on the effective stiffness of shear walls. Their results show that the axial compression ratio is the main influencing factor of the effective stiffness of shear walls. Huang et al.[21] and Sharifi et al.[22] studied the effective stiffness of shear walls in which the coupled shear wall were not involved, which are more common in practical projects. $\kappa$ is of great significance to the seismic performance of the entire structure. Fan et al.[5] studied the stiffness reduction coefficient and equivalent damping ratio of coupling beams by using SAP2000. The method adopted by Fan is effective and can accurately simulate the stiffness degradation of members under minor and moderate earthquakes. Hou et al.[6] carried out elastoplastic analysis to study the damage states of coupling beams and their stiffness reduction coefficients by using SAUSAGE and discussed the main influencing factors. Xiao et al.[7] developed a new method for estimating $\kappa$ and its effects on seismic response. First, the pre-determined yield mode design method was improved. Then, the actual $\kappa$ was calculated based on the inelastic analysis using ABAQUS. However, the finite element analysis is based on a series of model hypothesis, which will lead to non-negligible deviation between the analysis results and actual situation. The above studies only provide analysis methods and qualitatively analyzed the stiffness reduction coefficient of coupling beams. On the basis of 28 tests of the shaking table models by the Chinese Academy of Building Sciences in practical engineering, Chen et al. [23] studied the influence of the stiffness reduction coefficient and damping ratio of coupling beams on high-rise building structures and made design suggestions. However, they did not propose a calculation method for the stiffness reduction coefficient of coupling beam. Paulay et al. [8] proposed a calculating equation for the stiffness reduction coefficient of coupling beam in 1992, but the equation is only as a function of the effective depth-span ratio $(d / l)$, but the effects of longitudinal reinforcement ratio, and stirrup ratio are ignored. The analytical approaches proposed by $\mathrm{Vu}$ et al. are preferred over the methods above because they comprehensively consider all influencing factors, but the equations are obtained through data analysis and parametric modification, and the interaction mechanism of the influencing factors are not fully considered. Moreover, only the $l / h \leq 2.5$ coupling beams are involved in the analysis, limiting the application scope; if the coupling beam has a large span-depth or reinforcement ratio, the prediction value might be greater than $100 \%$, which does not occur in practice. Establishing a reasonable simplified analysis model and determining the interaction mechanism of the influencing factors of coupling beams help estimate the stiffness reduction coefficient of coupling beams. Bernardo et al.[24,25] modified the variable angle truss model, and the modified variable angle truss model can be used to effectively simulate the bending and torsion behaviors of precast concrete beams. According to the modified field theory, Shi et al.[26] proposed the calculation equation of the punching shear bearing capacity of slab, which was verified by the test results of 109 reinforced concrete slabs, proving that the modified field theory could effectively simulate the punching shear model of the concrete slabs. Besides, the reasonable simplified analysis model can also be used to analyze the stress of strengthening members. Dhahir et al.[27] analyzed the shear behavior of fiber reinforced polymer (FRP) strengthened beams by using the strut-and-tie model and proposed an equation for calculating the shear bearing capacity; the equation was verified by the test results of 45 deep beams. Corrosion, insufficient anchorage length of reinforcement and cracks deteriorate the strength and stiffness of semi-composite bridges over time, but the available codes and calculation methods fail to consider the influence of these factors, leading to potential safety hazards. 12 tests of semicomposite bridges were also carried out by Desnerck et al.[28] to study the influence of a single factor and multiple factors on the mechanical properties of semi-composite bridges, and correction suggestions were made to enhance the prediction effect of the strut-and-tie model on the bearing capacity of semi-composite bridges. The strut-and-tie model has the advantages of determined the force transfer mechanism and simple calculation, which are conductive to 
predicting the stiffness reduction coefficient of coupling beams.

Based on the strut-and-tie model, this study performs model analysis and parameter modification and then derives the calculation equation of $\kappa$, which is a function of the span-depth ratio, longitudinal reinforcement ratio, stirrup ratio and concrete compressive strength. The reliability of the equation is verified by comparison with the experimental results from the literature, and the parameters are further analyzed. The effects of various factors on $\kappa$ are studied, and design suggestions are made to avoid the rapid stiffness degradation of coupling beam. The study results provide a reference for the design and optimization of shear wall and core tube structures..

The remainder of this study is organized as follows. Chapter 3 presents the definition and existing calculation method of $\kappa$ and establishes a simplified analysis model. Chapter 4 proposes the theoretical equation and verifies its reliability and superiority by comparison with existing test data and calculation methods. Furthermore, relevant parameters are analyzed. Finally, Chapter 5 summarizes this study and draws conclusions.

\section{Methodology}

\subsection{Definition of $\boldsymbol{\kappa}$}

$\kappa$ is derived as follows:

$$
\kappa=\frac{K_{\mathrm{e}}}{K_{\mathrm{g}}} \frac{K_{\mathrm{e}}}{E_{\mathrm{c}} I_{\mathrm{g}}} \cdot \frac{l^{3}}{12}=\frac{I_{\mathrm{e}}}{I_{\mathrm{g}}}
$$

where $K_{\mathrm{e}}$ is the effective stiffness of the coupling beam, $K_{\mathrm{g}}$ denotes the initial stiffness of the coupling beam, $l$ represents the span of the coupling beam, $E_{\mathrm{c}}$ is the elastic modulus of concrete, $I_{\mathrm{e}}$ is the effective moment of inertia of the coupling beam, and $I_{\mathrm{g}}$ is the initial moment of inertia of the coupling beam.

The effective stiffness[29,30], which is generally the secant stiffness of the structure at $75 \%$ ultimate strength, can be obtained by the plotting method as shown in Fig. 1 .

The effective stiffness of coupling beams is given by:

$$
K_{\mathrm{e}}=\frac{V_{\mathrm{y}}}{\Delta_{\mathrm{y}}}
$$

where $V_{\mathrm{y}}$ is the yield lateral force, and $\Delta_{\mathrm{y}}$ is the yield displacement.

$\kappa=\frac{I_{\mathrm{e}}}{I_{g}}=0.67\left(1.8 \frac{l}{d}+0.4 \frac{l^{2}}{d^{2}}\right)\left(0.9+0.7 \rho_{\mathrm{v}}+1.1 \rho_{\mathrm{s}}\right)\left(0.5+\frac{11}{f_{\mathrm{c}}{ }^{\prime}}\right)$

where $f_{\mathrm{c}}^{\prime}$ is the compressive strength of concrete cylinder, $\rho_{\mathrm{v}}$ is the stirrup ratio of the coupling beam, and $l / d$ is the effective span-depth ratio.

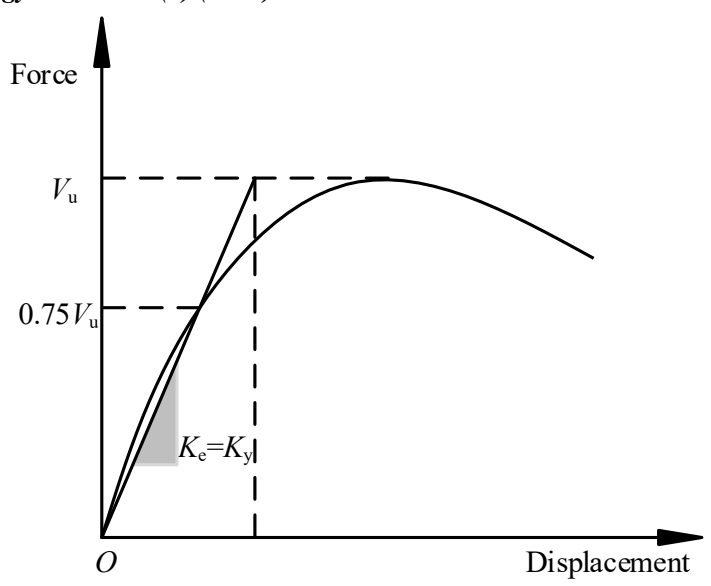

Fig. 1. Definition of effective stiffness

\subsection{Existing calculation methods}

\section{(1) NZS 3101[31]}

NZS 3101 recommends an equation for estimating $\kappa$ solely as a function of depth - span ratio $d / l$.

$$
I_{\mathrm{e}}=\frac{0.4 I_{\mathrm{g}}}{1+8(d / l)^{2}}
$$

where $d$ is the effective height of the coupling beam.

(2) ACI318-14[32]

ACI318-14 consists of two ways of calculating the stiffness reduction coefficient of CCBs, one is $0.35 E_{\mathrm{c}} I_{g}$, and the other is as Eq. (4):

$$
I_{\mathrm{e}}=\left(0.1+25 \rho_{\mathrm{s}}\right)\left(1.2-\frac{0.2 b}{d}\right) I_{\mathrm{g}}
$$

where $\rho_{\mathrm{s}}$ is the longitudinal reinforcement ratio, $b$ represents the width of the coupling beam, and $0.25 I_{\mathrm{g}} \leq I_{\mathrm{e}} \leq 0.5 I_{\mathrm{g}}$.

\section{(3) Paulay[8]}

The calculation method of $\kappa$ proposed by Paulay et al. is only a correlation function of effective depth-span ratio $d / l$, as shown in Eq.(5):

$$
I_{\mathrm{e}}=\frac{0.2 I_{\mathrm{g}}}{1+3(d / l)^{2}}
$$

(4) $\mathrm{Vu} \quad$ [9]

On the basis of the concrete truss model, $\mathrm{Vu}$ et al.[9] proposed two equations for estimating the stiffness reduction coefficients of CCBs and DCBs. The equation of the stiffness reduction coefficient of CCB is expressed as Eq. (6)

\subsection{Establishment of simplified analysis model}

A reasonable simplified analysis model is helpful to effectively determine the correlation of the influencing factors, but model assumptions lead to a deviation between the calculated value and the test result. Therefore, this study 
proposes the calculation equation of $\kappa$ via model analysis, which is further modified according to the existing test data.

Under the action of horizontal load, the wall limbs are bent and deformed, resulting in a vertical displacement difference at both ends of the coupling beam and forming the bending moment and shear force, as shown in Fig. 2(CB denotes the coupling beam).

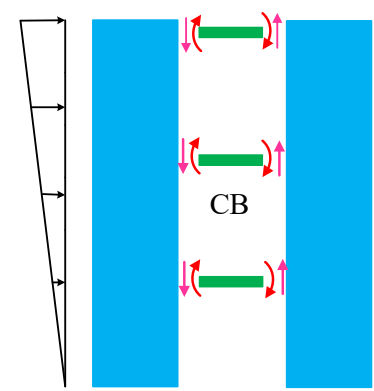

(a)Stress of coupling beam

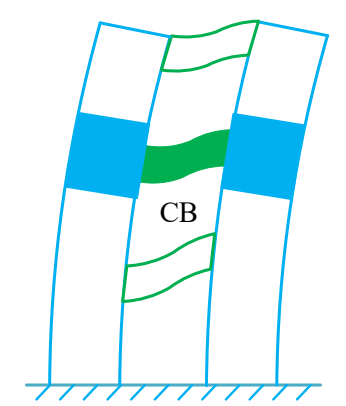

(b) Deformation characteristics of coupling beam
Fig.2. Force and deformation characteristics of coupling beam

Considering that the mechanical behavior of coupling beams under the action of floor slab [33-35] is complicated, the floor effect is seldom considered in the seismic test and analysis model. Thus, the slab effects have not been taken into consideration by the existing stiffness reduction coefficient calculation methods either. Accordingly, the effect of floor slab is ignored in this study. Assuming the wall limbs at both ends of the coupling beam are of the same stiffness, the reverse bend point method[36] can be combined with the force and deformation characteristics of the connecting beam(shown in Fig.1) to simplify the analytical approach to transforming coupling beam into the cantilever beam, as shown in Fig. 3-a. Assuming that the compressive stress is transferred to the support in the shortest path, and the deformation at the end of the coupling beam $\left(\Delta_{\text {end }}\right)$ is equal to $2 \Delta_{\mathrm{m}}\left(\Delta_{\mathrm{m}}\right.$ is the deformation in the middle portion of the coupling beam). The simplified analysis model (the strut-and-tie model) established in this study is shown in Fig. 3-b. And $\theta_{1}$ is the angle of the inclined strut:

$$
\tan \theta_{1}=2 d / l
$$

\section{Result Analysis and Discussion}

\subsection{Theoretical equation}

On the basis of the theoretical model in Section 3.3, the vertical deformation in the middle portion of the coupling beam can be obtained as:

$$
\Delta=\sum \frac{F f L}{E A}
$$

In Fig.3, the deformations of longitudinal chord $A B$, concrete compression strut $\mathrm{BC}$, and transverse tensile $\mathrm{BD}$ are shown in Table 1.

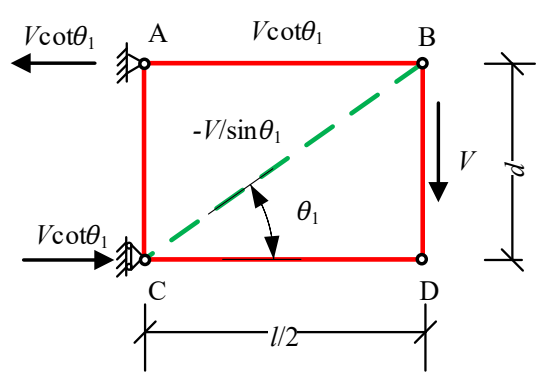

(b) Force of each component of the coupling beam

Fig. 3. Simplified analysis model of CCB

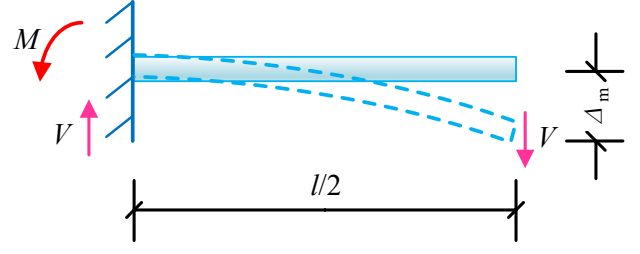

(a) Cantilever beam

Table 1. Vertical deformation of each member

\begin{tabular}{c|c|c|c|c|c}
\hline Member & $\boldsymbol{F}$ & $\boldsymbol{f}$ & $\boldsymbol{L}$ & $\boldsymbol{E} \boldsymbol{A}$ & Deformation \\
\hline $\mathrm{AB}$ & $V \cot \theta_{1}$ & $\cot \theta_{1}$ & $d \cot \theta_{1}$ & $E_{\mathrm{s}} A_{\mathrm{s}}$ & $V d \cot ^{3} \theta_{\mathrm{l}} /\left(E_{\mathrm{s}} A_{\mathrm{s}}\right)$ \\
$\mathrm{BC}$ & $-V / \sin \theta_{1}$ & $-1 / \sin \theta_{1}$ & $d / \sin \theta_{1}$ & $E_{\mathrm{c}} b d \cot \theta_{1}$ & $V \csc ^{3} \theta_{1} \sec _{1} /\left(b E_{\mathrm{c}}\right)$ \\
$\mathrm{BD}$ & $V$ & 1 & $d$ & $E_{\mathrm{v}} A_{\mathrm{v}}$ & $V d / E_{\mathrm{v}} A_{\mathrm{v}}$ \\
\hline
\end{tabular}

Note: $E_{\mathrm{s}}, E_{\mathrm{c}}$ and $E_{\mathrm{v}}$ are the elastic modulus of longitudinal reinforcement, concrete and stirrup respectively; $A_{\mathrm{s}}$ and $A_{\mathrm{v}}$ are the cross-sectional area of longitudinal reinforcement and stirrup respectively, $A_{\mathrm{s}}=b d \rho_{\mathrm{s}}, A_{\mathrm{v}}=b l \rho_{\mathrm{v}} / 2$.

The vertical deformation at the end of the coupling beam under yield force can be expressed as Eq. (9):

$$
\Delta_{\mathrm{y}, \text { end }}=\frac{2 d V_{\mathrm{y}} \cot ^{3} \theta_{1}}{\rho_{\mathrm{s}} E_{\mathrm{s}} b d}+\frac{2 V_{\mathrm{y}} \csc ^{3} \theta_{1} \sec \theta_{1}}{b E_{\mathrm{c}}}+\frac{4 d V_{\mathrm{y}}}{\rho_{\mathrm{v}} E_{\mathrm{v}} b l}
$$

On the basis of Eqs. (2), (7), and (9), the effective stiffness of the coupling beam can be written as Eq.(10):

$$
K_{\mathrm{e}}=\frac{b \rho_{\mathrm{v}} E_{\mathrm{c}} \cot \theta_{1}}{\frac{2 E_{\mathrm{c}} \rho_{\mathrm{v}}}{E_{\mathrm{s}} \rho_{\mathrm{s}}} \cot ^{4} \theta_{1}+2 \rho_{\mathrm{v}} \csc ^{4} \theta_{1}+\frac{2 E_{\mathrm{c}}}{E_{\mathrm{v}}}}
$$

Let $n_{\mathrm{vc}}=E_{\mathrm{v}} / E_{\mathrm{c}}, \xi=\rho_{\mathrm{v}} / \rho_{\mathrm{s}}$, and $n_{\mathrm{vs}}=E_{\mathrm{v}} / E_{\mathrm{s}}$, then, Eq. (10) can be transformed into:

$$
K_{\mathrm{e}}=\frac{n_{\mathrm{vc}} b \rho_{\mathrm{v}} E_{\mathrm{c}} \cot \theta_{1}}{2 \xi n_{\mathrm{vs}} \cot ^{4} \theta_{1}+2 n_{\mathrm{vc}} \rho_{\mathrm{v}} \csc ^{4} \theta_{1}+2}
$$

Based on Eqs. (1) and (11), $\kappa$ is computed as follows: 


$$
\kappa=\frac{4 n_{\mathrm{vc}} \rho_{\mathrm{v}} \frac{l^{4}}{d h^{3}}}{\xi n_{\mathrm{vs}} \frac{l^{4}}{d^{4}}+n_{\mathrm{vc}} \rho_{\mathrm{v}}\left(\frac{l^{2}}{d^{2}}+4\right)^{2}+16}
$$

where $h$ is the height of the coupling beam.

The Chinese Code for Design of Concrete Structures GB50010-2010[37] suggests the modulus of elasticity of concrete to be calculated as follows:

$$
E_{\mathrm{c}}=\frac{10^{5}}{2.2+34.7 / f_{\mathrm{cu}, \mathrm{k}}}
$$

Given the commonly used steel have similar elastic modulus, and assuming that $E_{\mathrm{s}}=E_{\mathrm{v}}=2.0 \times 10^{5} \mathrm{MPa}$, then $n_{\mathrm{vs}}=1, n_{\mathrm{vs}}=n_{\mathrm{sc}}=n$, and the modulus ratio can be calculated as:

$n=4.4+\frac{69.4}{f_{\mathrm{cu}, \mathrm{k}}}$

Because the effective depth $d$ is always close to $0.9 h$, hence assuming that $d=0.9 h$, then Eq. (14) can be transformed into Eq. (15):

$\kappa=\frac{4.44 n \rho_{\mathrm{v}} \rho_{\mathrm{s}} l^{4} / h^{4}}{1.52 \rho_{\mathrm{v}} l^{4} / h^{4}+n \rho_{\mathrm{v}} \rho_{\mathrm{s}}\left(1.23 l^{2} / h^{2}+4\right)^{2}+16 \rho_{\mathrm{s}}}$

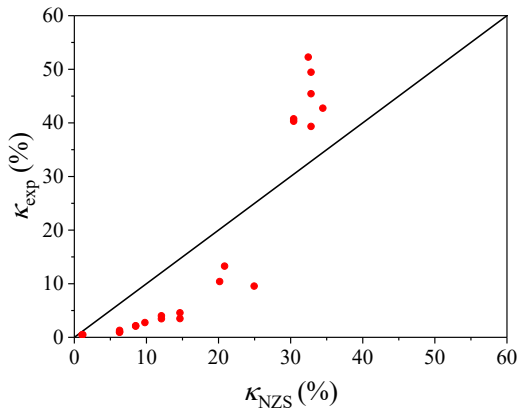

(a) NZS3101-Eq.(3)

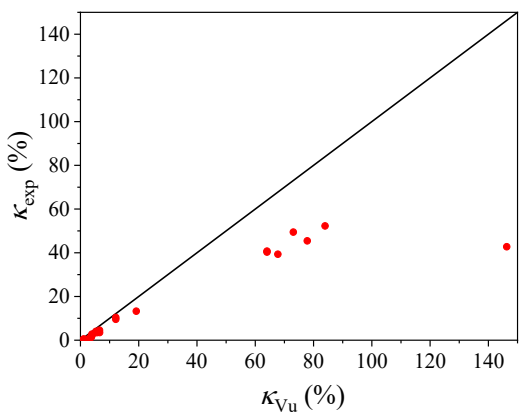

(d) $\mathrm{Vu}$-Eq.(6)

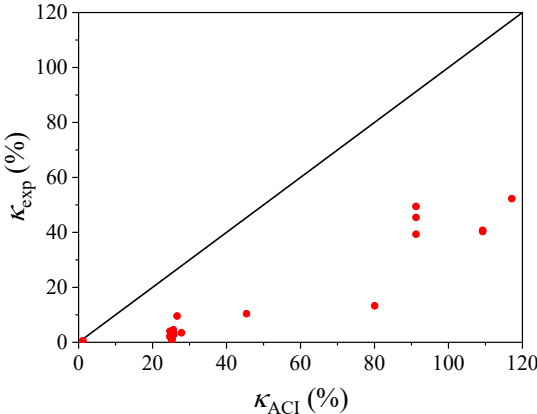

(b) ACI318-14-Eq.(4)

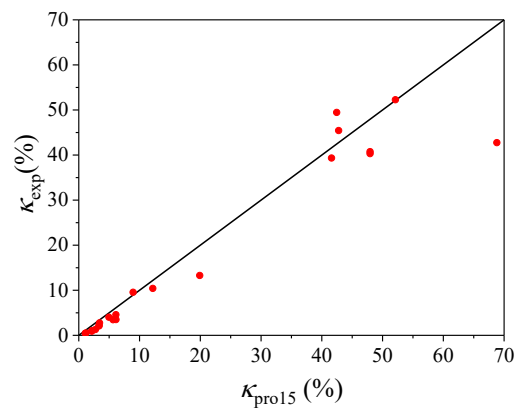

(e) Eq. (15)

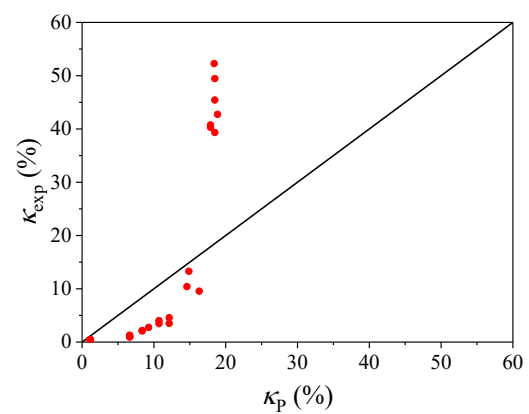

(c) Paulay-Eq.(5)

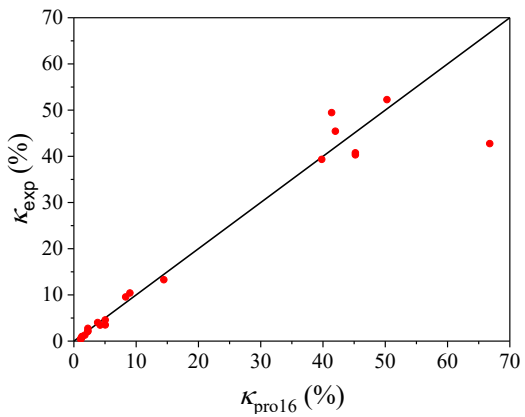

(f) Eq. (16)

Fig. 4. Comparison between experimental results and prediction results 
Table 2. Comparison between test results and prediction results for stiffness reduction coefficient of CCBs

\begin{tabular}{|c|c|c|c|c|c|c|c|c|c|c|c|c|c|}
\hline Ref & Specimen & $\begin{array}{c}f_{\mathrm{cu}} \\
(\mathrm{MPa})\end{array}$ & $\begin{array}{c}\rho_{\mathrm{v}} \\
(\%)\end{array}$ & $\begin{array}{c}\rho_{\mathrm{s}} \\
(\%)\end{array}$ & $l / h$ & $l / d$ & $\begin{array}{c}\kappa_{\text {exp }} \\
(\%)\end{array}$ & $\begin{array}{l}\kappa_{\text {pro15 }} \\
(\%)\end{array}$ & $\begin{array}{l}\kappa_{\exp } / \\
\kappa_{\text {pro15 }}\end{array}$ & $\begin{array}{l}\kappa_{\text {pro16 }} \\
(\%)\end{array}$ & $\begin{array}{l}\kappa_{\text {exp }} / \\
\kappa_{\text {prol6 }}\end{array}$ & $\begin{array}{c}\kappa_{\mathrm{Vu}} \\
(\%)\end{array}$ & $\begin{array}{l}\kappa_{\exp } / \\
\kappa_{\mathrm{Vu}}\end{array}$ \\
\hline$[38]$ & Unit1 & 50.2 & 0.55 & 1.31 & 2.5 & 2.85 & 10.41 & 12.18 & 0.854 & 9.00 & 1.156 & 12.14 & 0.879 \\
\hline [39] & Specimen2 & 56.4 & 0.86 & 2.61 & 2.5 & 2.95 & 13.28 & 19.91 & 0.667 & 14.44 & 0.920 & 19.16 & 0.693 \\
\hline \multirow{5}{*}{ [40] } & CCB1 & 52 & 1.12 & 0.47 & 1.17 & 1.22 & 0.99 & 2.15 & 0.461 & 1.31 & 0.757 & 3.14 & 0.315 \\
\hline & CCB2 & 52 & 1.12 & 0.46 & 1.40 & 1.47 & 2.08 & 3.33 & 0.624 & 2.24 & 0.928 & 3.94 & 0.528 \\
\hline & CCB3 & 52 & 1.12 & 0.58 & 1.75 & 1.86 & 3.46 & 5.64 & 0.613 & 4.22 & 0.820 & 5.63 & 0.615 \\
\hline & CCB4 & 52 & 1.12 & 0.51 & 2 & 2.15 & 3.50 & 6.12 & 0.572 & 5.04 & 0.694 & 6.58 & 0.532 \\
\hline & $\mathrm{CCB} 12$ & 52 & 1.68 & 0.47 & 1.17 & 1.22 & 1.30 & 2.74 & 0.475 & 1.77 & 0.735 & 3.71 & 0.351 \\
\hline \multirow{4}{*}{ [41] } & MCB1 & 52.5 & 1.12 & 0.47 & 1.17 & 1.22 & 0.94 & 2.14 & 0.438 & 1.31 & 0.720 & 3.14 & 0.300 \\
\hline & MCB2 & 52.5 & 1.12 & 0.46 & 1.4 & 1.47 & 2.17 & 3.33 & 0.652 & 2.24 & 0.970 & 3.92 & 0.553 \\
\hline & MCB3 & 52.5 & 1.12 & 0.47 & 1.75 & 1.86 & 4.02 & 4.96 & 0.811 & 3.82 & 1.052 & 5.32 & 0.756 \\
\hline & MCB4 & 52.5 & 1.12 & 0.51 & 2 & 2.15 & 4.58 & 6.11 & 0.750 & 5.03 & 0.911 & 6.56 & 0.699 \\
\hline [42] & $\mathrm{P} 01$ & 61.1 & 0.84 & 0.52 & 1.5 & 1.61 & 2.76 & 3.42 & 0.807 & 2.25 & 1.229 & 3.94 & 0.701 \\
\hline [43] & FB33 & 51.8 & 0.61 & 0.61 & 3.33 & 3.64 & 9.56 & 8.94 & 1.069 & 8.32 & 1.149 & 12.14 & 0.787 \\
\hline \multirow{2}{*}{ [44] } & L1 & 37.3 & 1.15 & 2.92 & 5.36 & 6.05 & 49.46 & 42.45 & 1.165 & 41.39 & 1.195 & 73.06 & 0.677 \\
\hline & $\mathrm{L} 2$ & 37.3 & 1.61 & 2.92 & 5.36 & 6.05 & 45.44 & 42.77 & 1.062 & 41.99 & 1.082 & 77.84 & 0.584 \\
\hline \multirow{5}{*}[45]{} & L-A & 37.3 & 1.15 & 3.85 & 5.17 & 5.86 & 52.27 & 52.11 & 1.003 & 50.27 & 1.040 & 83.95 & 0.623 \\
\hline & L-C1 & 37.3 & 1.15 & 3.65 & 4.46 & 5.04 & 40.31 & 47.94 & 0.841 & 45.20 & 0.892 & 64.02 & 0.630 \\
\hline & L-C2 & 37.3 & 1.15 & 3.65 & 4.46 & 5.04 & 40.76 & 47.94 & 0.850 & 45.20 & 0.902 & 64.02 & 0.637 \\
\hline & L-D & 37.3 & 0.64 & 2.92 & 5.36 & 6.05 & 39.34 & 41.60 & 0.946 & 39.80 & 0.989 & 67.76 & 0.581 \\
\hline & L-E & 37.3 & 1.12 & 5.47 & 5.83 & 7.06 & 42.75 & 68.81 & 0.621 & 66.77 & 0.640 & 146.3 & 0.292 \\
\hline \multicolumn{2}{|l|}{ Mean } & & & & & & & & 0.777 & & 0.939 & & 0.587 \\
\hline \multicolumn{2}{|c|}{ Variable coefficient } & & & & & & & & 0.214 & & 0.175 & & 0.164 \\
\hline
\end{tabular}

Table 3. Statistic indicators of estimated results for stiffness reduction coefficient of CCBs

\begin{tabular}{|c|c|c|c|c|c|c|c|c|}
\hline \multirow{2}{*}{ Theoretical equation } & \multicolumn{2}{|l|}{$l / h \leq 2.5$} & \multicolumn{2}{|c|}{$2.5<l / h \leq 5$} & \multicolumn{2}{|l|}{$l / h>5$} & \multicolumn{2}{|l|}{ Total } \\
\hline & $\chi_{\mathrm{m}}$ & $\chi_{\mathrm{cov}}$ & $\chi_{\mathrm{m}}$ & $\chi_{\mathrm{cov}}$ & $\chi_{\mathrm{m}}$ & $\chi_{\mathrm{cov}}$ & $\chi_{\mathrm{m}}$ & $\chi_{\text {cov }}$ \\
\hline NZS3101 & 0.302 & 0.142 & 1.016 & 0.548 & 1.388 & 0.174 & 0.681 & 0.538 \\
\hline Paulay & 0.355 & 0.226 & 1.706 & 0.970 & 2.474 & 0.291 & 1.088 & 1.025 \\
\hline $\mathrm{ACI} 318$ & $0.117(0.118)$ & 0.060 & 0.367 & 0.007 & 0.440 & 0.099 & 0.235 & 0.164 \\
\hline $\mathrm{Vu}$ & 0.577 & 0.183 & 0.684 & 0.089 & 0.551 & 0.040 & 0.586 & 0.164 \\
\hline Eq. (15) & 0.665 & 0.163 & 0.920 & 0.129 & 0.960 & 0.117 & 0.777 & 0.214 \\
\hline Eq. (16) & 0.908 & 0.174 & 0.981 & 0.146 & 0.989 & 0.109 & 0.939 & 0.175 \\
\hline
\end{tabular}

Note: $\chi_{\mathrm{m}}$ and $\chi_{\mathrm{cov}}$ are the average value and variation coefficient of $\chi$, respectively. The datas in brackets are the calculation results when ACI $318-14$ takes the stiffness reduction coefficient coupling beam of 0.35 .

From the comparisons in Tables 2 and 3 and Fig. 4, the following conclusions can be drawn:

(1) The theoretical equations provided by NZS 3101 and Paulay only consider the influence of the effective spandepth ratio but ignore the affecting factors of longitudinal reinforcement ratio and stirrup ratio, thus leading to overestimation or underestimation of the stiffness reduction coefficient of CCBs. The predicted values were higher than the test results when $l / h \leq 2.5$, but lower than the test values when $l / h>5$. The prediction of CCBs using Eq. (5) (ACI318) was too large. Although the theoretical equation proposed by $\mathrm{Vu}$ et al. comparatively considers the effects of the span-depth ratio, longitudinal reinforcement ratio, stirrup ratio and concrete compressive strength, the comparison shows that the stiffness reduction coefficients of CCBs are overestimated by $\mathrm{Vu}$ (Eq. 5), and the prediction to L-3 [45] is $146.3 \%$, which violates the engineering practice.

(2) The proposed calculation Eq. (15) can predict the stiffness reduction coefficient of CCBs well, but the prediction is slightly higher than the test results, because the Bauschinger effect and the bond-slip deformation are not considered. The modified equation, Eq. (16), offers a better estimation. The average value of $\kappa_{\text {exp }} / \kappa_{\text {prol6 }}$ is 0.939 , and the coefficient of variation is 0.175 , indicating that Eq. (16) can accurately estimate the stiffness reduction coefficient of CCBs.

\subsection{Parameter analysis}

For a better understanding of the influencing factors of $\kappa$, parametric analyses of Eq. (16) are carried out to study the effects of span-depth ratio $l / h$, longitudinal reinforcement ratio $\rho_{\mathrm{s}}$, stirrup ratio $\rho_{\mathrm{v}}$, and the compressive strength of concrete cube $f_{\text {cu }}$. The parameters are listed in Table 4, and the analysis results are shown in Fig. 6. Specimen Unit 1 with the span-depth ratio of 2.5[38] is taken as the reference specimen in the parametric study, the details is shown in Fig. 5 , and the concrete cube compressive strength $f_{\text {cu }}$ is 50.2 MPa.

Table 4. Parameter variations of CCBs

\begin{tabular}{c|c|c|c|c}
\hline Parameters & \multicolumn{4}{|c}{ Various factors } \\
\hline$l / h$ & 1.5 & 2.5 & 3.5 & 5 \\
$\rho_{\mathrm{v}} / \%$ & 0.55 & 1.15 & 1.61 & \\
$\rho_{\mathrm{s}} / \%$ & 0.61 & 1.29 & 2 & \\
$f_{\mathrm{cu}} / \mathrm{MPa}$ & 40 & 50 & 60 & \\
\hline
\end{tabular}

Fig. 6 shows correlation between the effects of the impacting factors on the stiffness reduction coefficients of $\mathrm{CCB}$ and that $\kappa$ increases with the span-depth ratio, longitudinal reinforcement ratio, and stirrup ratio. The spandepth ratio is the most significant factor on the stiffness reduction coefficient of $\mathrm{CCB}$, which increases significantly 


\section{Journal of Engineering Science and Technology Review 13 (5) (2020) 82 - 89}

with the longitudinal reinforcement ratio when the coupling beam has a large span-depth ratio. When the span-depth ratio is small, the stirrup ratio has a bigger role. $\kappa$ decreases with the increase of the concrete compressive strength, but the effect is less important. This change trend is basically consistent with the former study by $\mathrm{Vu}$ et al.[9]

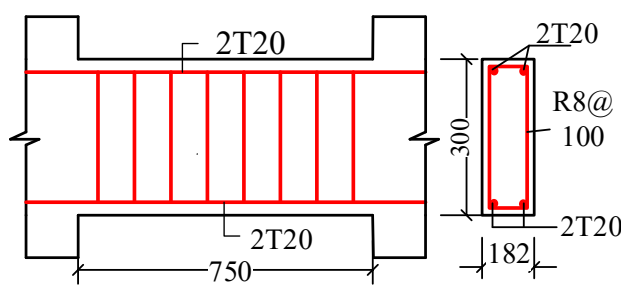

Fig. 5. Details of Unit1(in mm)

The stiffness reduction coefficient of coupling beam can reflect the stiffness degradation degree when the coupling beam yields. The span-depth ratio is the main influencing factor of the deformation performance and failure mode and directly affects the stiffness reduction coefficient of CCB. The coupling beam with a small spandepth ratio cannot give full play to its deformation performance due to excessive shear force, resulting in rapid stiffness degradation and the decrease of $\kappa$. When $l / h$ is large, the coupling beam has a strong deformation capacity, the stiffness degrades slowly, and $\kappa$ increases accordingly. Shear force is enhanced with the decrease of the span-depth ratio, and stirrup ratio increase can effectively enhance the shear capacity, preventing the premature shear failure of coupling beams and can slow down the stiffness degradation. Bending failure plays a controlling role for coupling beam with a large span-depth ratio. Within a certain range, the effective stiffness of coupling beams can be improved by increasing the longitudinal reinforcement ratio. Enhancing the concrete compressive strength can improve both the effective and initial stiffness of the coupling beam, but the initial stiffness increases faster, thereby decreasing the stiffness reduction coefficient. Conventionally used concrete has a similar elastic modulus. Thus, the stiffness reduction coefficient of the coupling beam has little influence.

The stiffness reduction coefficient of coupling beam should not be extremely small to avoid the sudden change of internal force, which will affect the energy dissipation mechanism and the failure mode. On the basis of the analysis above, the use of a double-coupling-beam is suggested to increase the stiffness reduction coefficient of the coupling beam when a small span-depth ratio is unavoidable.

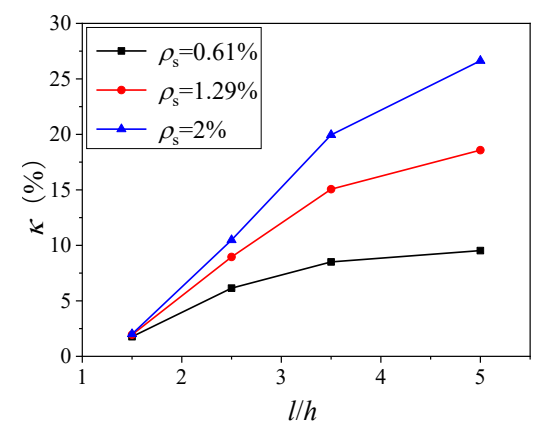

(a) $f_{\mathrm{cu}}=50 \mathrm{MPa}, \rho_{\mathrm{v}}=0.55 \%$

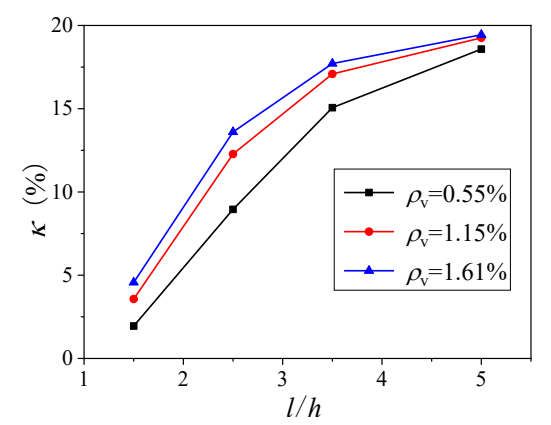

(b) $f_{\mathrm{cu}}=50 \mathrm{MPa}, \rho_{\mathrm{s}}=1.29 \%$

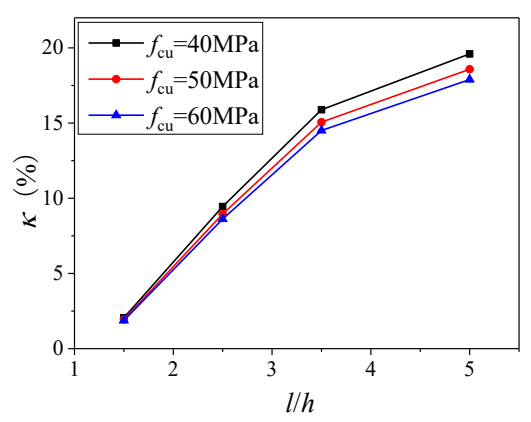

(c) $\rho_{\mathrm{v}}=0.55 \%, \rho_{\mathrm{s}}=1.29 \%$

Fig. 6. Influence of various parameters on stiffness reduction coefficients of CCBs

\section{Conclusion}

To effectively predict the stiffness reduction coefficient of $\mathrm{CCBs}$ and reveal the correlation of various influencing factors, this study derived the calculation equation by model analysis and parameter modification. Parameter analysis was carried out, and the following conclusions could be drawn:

(1) Eq. (16) is a correlation function of concrete compressive strength, longitudinal reinforcement ratio, stirrup ratio, and span-depth ratio. The reliability of the equation was verified by comparison with the test results obtained from the literature. The proposed method has the advantages of high prediction accuracy, wide application scope, and comprehensive consideration.

(2) The stiffness reduction coefficient of CCBs increases with the span-depth ratio, longitudinal reinforcement ratio, and stirrup ratio, and the factors are interrelated. The spandepth ratio $(l / h)$ is the main influencing factor. Furthermore, when the coupling beam has a large span-depth ratio, $\kappa$ significantly increases with the longitudinal reinforcement ratio; $\kappa$ decreases with the increase of the concrete compressive strength, but the influence is less obvious.

(3) When the coupling beam has a small span-depth ratio, a double-coupling-beam is suggested to avoid the excessive stiffness degradation of the coupling beam stiffness during yielding; otherwise, the structural failure mode and the energy dissipation mechanism will be influenced.

A theoretical equation is proposed to effectively predict the stiffness reduction coefficient of CCBs in this study. Compared with the existing methods, the proposed equation has the advantages of comprehensive consideration and wide application scope. However, this study only analyzed CCBs, and the calculation equation did not consider the floor effect. Other types of coupling beams and the floor effect should be further studied.

\section{Acknowledgements}

This work was supported by National Natural Science Foundation of China (NO. 51278181 and 51578235) and Provincial University Student Innovation and Entrepreneurship Training Program of Hunan, China (NO. S202011527007)

This is an Open Access article distributed under the terms of the Creative Commons Attribution License

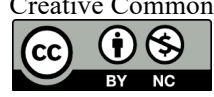




\section{References}

1. Ji, X. D., Xu, M. C., Zhuang, Y. C., Jiang, Z., "Fragility curves of reinforced concrete shear walls and coupling beams". Engineering Mechanics, 37(4), 2020, pp.205-216. (in Chinese)

2. Liu, J., Wu, Y. T., Yang, Y. B., "Experimental study on seismic behavior of composite steel plate coupled wall system with bolt connection". Journal of Building Structures, 39(S1), 2018, pp.136143. (in Chinese)

3. Hou, W., Xu, S. L., Ji, D. S., "Cyclic performance of steel platereinforced high toughness-concrete coupling beams with different span-to-depth ratios". Journal of Structural Engineering, 144(10), 2018, pp. 1-11. (in Chinese)

4. Jiang, H. J., Huang, Y. L., Li, K. X., "Replaceable coupling beam with combined dampers". Journal of Hunan University (Natural Sciences), 47(1), 2020, pp. 26-35. (in Chinese).

5. Fan, Z., Liu, Y. B., Xing, C., "Study on determination method of stiffness reduction factor of coupling beams in shear wall structures". Building Structure, 45(23), 2015, pp. 16-20. (in Chinese)

6. Hou, X. W., Wang, Y., Yang, Z. Y., "Application of method on stiffness reduction coefficient of coupling beam". Building Structure, 48(9), 2018, pp.28-33(in Chinese).

7. Xiao, C. Z., Deng, F., "Study on deformation of flexural stiffness reduction factor of coupling beams in frame-core structures". Journal of Building Structures, 39(10), 2018, pp.164-173. (in Chinese)

8. Paulay, T., Priestley, M. J. N., "Seismic design of reinforced concrete and masonry buildings". New York: Wiley, USA, 1992, pp.99-102.

9. $\mathrm{Vu}$, N. S., Li, B., Beye, K., "Effective stiffness of reinforced concrete coupling beams". Engineering Structures, 76(October), 2014, pp.371-382.

10. Tian, J. B., Shi, Q. X., Tao, Y., Liu Y. H., "Research on mechanics and deformation performance of plate-reinforced composite coupling beams with small span-to-depth ratio". Journal of Building Structures 37(12), 2016, pp.83-96. (in Chinese)

11. Tian, J. B., Shi, Q. X., Wang, N., "Shear Strength of platereinforced composite coupling beams with small span-to-depth ratio using softened strut-and-tie model". Engineering Mechanics, 33(5), 2016, pp.142-149. (in Chinese)

12. Hou, W., Chen, B., Guo, Z. X., Zhang, J., "Experimental study on seismic behavior of embedded steel plate reinforced concrete coupling beams". China Civil Engineering Journal, 50(2), 2017, pp.9-18. (in Chinese)

13. Wang, M. F., Luo, D., Hu, Z. Q., "Seismic performance of steelenhanced damping concrete core walls with concealed steel plate bracings". Engineering Structures, 213(June), 2020, pp. 1-23.

14. Wang, M. F., Hu, Z. Q., Luo, D., "Study on seismic performance of high damping concrete core walls with steel plate concealed bracings of different aspect ratio". Earthquake Engineering and Engineering Vibration, 31(11), 2018, pp.37-47.(in Chinese)

15. Chen, C., Lu, X. L., Jiang, C., "Design method of reinforced concrete structure with replaceable coupling beams". Word Earthquake Enginnering, 34(8), 2018, pp.10-24.(in Chinese)

16. Li, T., Zhang, S., Xu, Z. H., "Quasi-static test and numerical simulation of reinforced concrete coupled shear walls with segmental coupling beams". China Civil Engineering Journal, 53(4), 2020, pp.38-49.(in Chinese)

17. Farsi, A., Keshavarzi, F., Pouladi, P., Mirghaderi, R., "Experimental study of a replaceable steel coupling beam with an end-plate connection". Journal of Constructional Steel Research, 122(July), 2016, pp.138-150.

18. Ataei, A., Bradford, M. A., Liu, X., "Experimental study of composite beams having a precast geopolymer concrete slab and deconstructable bolted shear connectors". Engineering Structures, 114(May), 2016: pp.1-13.

19. Hou, H. T., Zang, Z. Y., Lu, Y. X., "Push-out tests of shear connectors for new for assembled steel-concrete composite beams"., Engineering Mechanics, 37(2), 2020, pp.201-210.

20. Chairunnisa, N., Satyarno, I., Muslikh., Aminullah, A., "Analysis and design of shear wall coupling beam using hybrid steel truss encased in reinforced mortar", 171(Complete), 2017, pp.940-947.

21. Huang, Y., Hu X. F., Wan, X. W., Hong, L. L., "Effective stiffness of reinforced concrete shear wall under lateral load". Journal of Hunan University(Natural Sciences), 46(7), 2019, pp.11-18.(in Chinese)
22. Sharifi, M., Shafieian, M., "Effective stiffness of concrete shear walls based on statistical analysis". Structural Concrete, 19(6), 2018, pp.1560-1576.

23. Chen, C. H., Wang, C. K., Zhang, H., "Edification of shaking table test on structure design of high-rise buildings". Journal of Building Structures, 41(7), 2020, pp.1-14.(in Chinese)

24. Bernardo, L. F. A., Teixeirab, M. M., "Modified softened trussmodel for prestressed concrete beams under torsion". Journal of Building Engineering, 19(September) 2018, pp. 49-61.

25. Bernardo, L. F. A., Teixeirab, M. M., "Refined softened-truss model with efficient solution procedure for reinforced concrete members under torsion combined with bending". Structures, 26(May), 2020, pp. 651-669.

26. Shi, Q. X., Jin, Y. L., "Punching shear strength of RC slabs based on modified compression field theory". Industrial Construction, 49(6) 2019, pp.94-98.(in Chinese)

27. Dhahir, M. K., "Strut and tie modeling of deep beams shear strengthened with FRP laminates", Composite Structures, 193(Jun), 2018, pp.247-259.

28. Dhahir, M. K., Lees, J. M., Morly, C. T., "Strut-and-tie models for deteriorated reinforced concrete half-joints", Engineering Structures, 161(April), 2018, pp.41-54

29. Oviedo, R., Gutierrez, S., Santa, M. H., "Experimental evaluation of optimized strut-and-tie models for a dapped beam". Structural concrete, 17(3), 2016,pp.469-480

30. Wei, W., Shao, C. J., Xiao, Z. H., "Experimental study on effective stiffness of reinforced concrete hollow piers". China Civil Engineering Journal, 52(10), 2019, pp.101-110.(in Chinese)

31. NZS 3101. "Concrete structures standard". Wellington: the trading arm of the Standards Council, New Zealand, 1995, pp.293-293.

32. ACI 318-14. "Building code requirements for structural concrete". Farmington Hills: American Concrete Institute, USA, 2014, pp.72-72.

33. Kotsovou, G. M., Cotsovos, D. M., "Shear failure criterion for RC T-beams". Engineering Structures, 160(April), 2018, pp.44 - 55.

34. Men, J. J., Xiong, L. Q., Lei, M. K., "Seismic performance of reinforced concrete column-steel beam subassemblies considering effect of RC slab". Journal of Building Structures, 40(12), 2019, pp.69-87.(in Chinese)

35. Du, K., Teng, N., Yan, D., "Experimental study on the effect of floor slab on the progressive collapse resistance of RC spatial frame structure". China Civil Engineering Journal, 52(6), 2019, pp.1423.(in Chinese)

36. Lin, L. P., Liu, K. D., He, J. Q., "Numerical method for consolidation factor on reserve bend point". Journal of Railway Science and Engineering, 17(3), 2020, pp. 623-627.(in Chinese)

37. GB 50010-2010."Code for design of concrete structures". Beijing: China Architecture and Building Press, China, 2011, pp. 287-287 (in Chinese)

38. Lam, W. Y., Su, R. K. L., Pam, H. J., "Experimental study on embedded steel plate composite coupling beams". ASCE Journal of Structural Engineering, 131(8), 2005, pp.1294-1302.

39. Lam, W. Y., Su, R. K. L., Pam, H. J., "Strength and ductility of embedded steel composite coupling beams". Advances in Structural Engineering, 6(1), 2003, pp.23-35.

40. Kwan, A. K. H., Zhao, Z. Z., "Cyclic behaviour of deep reinforced concrete coupling beams". Structures and Buildings, 152(3), 2002, pp.283-293.

41. Kwan, A. K. H., Zhao, Z. Z., "Testing of coupling beams with equal end rotations maintained and local joint deformation alloweds". Structures and Buildings, 152(1), 2002, pp.67-78.

42. Galano, L., Vignoli, A., "Seismic Behavior of short coupling beams with different reinforcement layouts". ACI Structural Journal, 97(6), 2000, pp.876-885.

43. Naish, D. A. B., "Testing and modeling of reinforced concrete coupling beams". Doctoral Dissertation of University of California, USA, 2010, 35-113.

44. Liu, Z. Q., Wu, B., Lin, S. S., "Study on seismic performance of reinforced concrete coupling beams". Earthquake Engineering and Engineering Vibration, 23(5), 2003, 117-124.(in Chinese)

45. Wu, B., Liu, Z. Q., Lin, S. S., "Experimental study on seismic performance of existing reinforced concrete coupling beams in Hongkong". World Earthquake Engineering, 18(2), 2002, pp.9-16.(in Chinese 